\title{
Moral Identity in Adolescence
}

\author{
Amani Faisal Qashmer, Ph.D \\ Assistant professor, Educational Psychology Department, College of Education, University of Jordan
}

\begin{abstract}
This paper describes a study performed to conceptualize moral identity development among Jordanian adolescents, and to test for age and gender differences. Data came from four local schools sample (N: 321; 10-15 years of age) of adolescents. All variables were self-report. The measure was the Moral Identity Scale by Aquino and Reed (2002), which showed good reliability, and validity. Moral identity was unrelated to age and gender. The involvement in school activities was not related to moral identity. Recommendations and implications of future research were discussed.
\end{abstract}

Keywords: moral identity, adolescents in Jordan.

DOI: $10.7176 /$ JEP/11-9-09

Publication date:March $31^{\text {st }} 2020$

\section{Introduction}

As proposed by Erikson (1963) an identity is embedded in the core of one's being. Identity is a central essence of the individual; it is formed inside and it reflects on the outside. Developing a sense of identity is a main task of adolescence (Erikson, 1968). Identity means the individual's definition of who he or she is. Morality is another developmental feature that significantly develops during adolescence. It represents care (Moshman, 2005), justice (Berkowitz, 2012b; Bock \& Samuelson, 2015; Moshman, 2005), and concern for human welfare (Berkowitz, 2012b; Moshman, 2004).

In early adolescence identity and morality integrate and moral identity extends into adulthood (Damon, 1984; Erikson, 1968; Berkowitz, 2012a). Moral identity is the person's degree of seeing his or her moral character as a main part of his or her self-concept (Bock \& Samuelson, 2015).

The main developmental contexts for morality and identity during adolescence are family and school (Bock \& Samuelson, 2015; Frimer \& Walker, 2009). School as a social context plays a significant role in the development of adolescent's identity. It mainly influences the moral facet of one's identity (Bock \& Samuelson, 2015, Moshman, 2005).

\section{Theoretical framework}

A key element of one's character is moral identity. Moral identity is defined as the individual's degree of considering his or her moral character as a central part of his or her self-concept (Bock \& Samuelson, 2015). There are some discussions in literature about identity development and moral development in Jordan; however, there is no empirical research to support this discussion. Betawi (2018) is one of the moral studies in Jordan. She looked at moral development in childhood. Upon reviewing the literature, a gap was present because no research has looked at its development among Jordanian adolescents. However, adolescence is the significant stage for moral development.

This study investigates moral identity development due to three variables; age, gender and school activity involvement. The first variable is age represented by school level (i.e. secondary school). Age had not been widely examined in most research on moral identity either. Some research has shown that moral identity development is not related to age (Hardy et al., 2013; Krettenauer, 2011; Pratt et al., 2003). The second variable is gender. Gender had also not been widely examined in the research on moral identity. Some research found that there was a difference in moral identity between males and females (e.g., Hardy, 2006, Hardy et al., 2013). Other research found females to be higher on moral identity than males (e.g., Hardy, 2006). Other studies have not found any gender difference (e.g., Aquino \& Reed, 2002). The third variable is school activity involvement. Betawi (2018) found that the school plays a major role in children's moral development. The current study mainly studied adolescence.

It is important to mention here that this study is the first to address moral identity of adolescents in Jordan. It will shed light on age and gender differences in moral identity through adolescence. It will also examine the influence of school activities on adolescents' moral identity. Finally, this study will encourage other researchers to investigate adolescents' moral identity from different angles. This study focused on these variables for being main factors related to the development of moral identity.

\section{Research questions}

The current study is a preliminary study of moral identity of adolescents in Jordan. For the purpose of this study, moral identity is defined as the person's degree of seeing his or her moral character as a central part of his or her 
self-concept (Bock \& Samuelson, 2015), which mainly develops in adolescence. Therefore, the following questions were generated:

1. Is there a difference in moral identity development according to age?

2. Is there a difference in moral identity development according to gender?

3. Is there a difference in moral identity development according to the involvement in school activities?

\section{Methods}

\subsection{Participants}

The population of the study consisted of adolescents who are enrolled in international programs in Amman, Jordan. Four schools were randomly selected. One hundred students were randomly selected from each school and were given the questionnaire. A total of 321 adolescents agreed to participate in the study by filling the questionnaire. 154 were males, 162 were females and 5 students did not reveal their gender.

\subsection{Procedures and measures}

A descriptive study was employed for the objective of the study. A questionnaire was conducted to measure moral identity. The questionnaire consisted of two sections. The first section solicits demographic data about participants such as age, gender and involvement in school activities. The second section consists of the Moral Identity Scale (MIS) developed by Aquino and Reed (2002), the MIS consists of nine stimulus traits (caring, compassionate, fair, friendly, generous, helpful, hardworking, honest, and kind), and 13 items assessing self-importance of these traits (e.g. It would make me feel good to be a person who has these characteristics), which measure moral identity. The measure includes two subscales: (a) Symbolization and (b) Internalization. Participants answered the 13 items (see Appendix A) using a five-point Likert scale $(1=$ strongly disagree, 5 = strongly agree).

Aquino and Reed (2002) report acceptable internal consistency reliabilities of .77 and .71 for Symbolization and Internalization, respectively. The reliability of this instrument for the sample of this study is acceptable but different from the original reliability reported by the authors. Cronbach's alpha was calculated as the reliability statistic of the MIS $(\alpha=.653)$.

\subsection{Data analysis}

The data collected for the current study were analyzed using the Statistical Package for the Social Sciences. Descriptive analysis was used to answer questions 1 and 2 with means, standard deviation and means percentage. One-way analysis of variance (ANOVA) was used to test for age differences to answer question 1, while T-test was used to answer question 2. One-way analysis of variance (ANOVA) was also used to determine the significance of activity involvement on moral identity among Jordanian adolescents and their preferred activities (question 3).

\section{Results}

\subsection{Moral identity and age}

To answer research question 1 that addressed the adolescents' age, descriptive statistical analysis was conducted to provide information about adolescents' age. Means, standard deviations and means percentage were computed. Results indicated that there is no significant difference in moral identity development due to age. As shown in Table 1.

Table 1. Participants' age and moral identity

\begin{tabular}{|l|r|r|r|}
\hline age & Mean & N & \multicolumn{1}{|c|}{ Std. Deviation } \\
\hline 12 years old & 46.9718 & 71 & 7.18326 \\
\hline 13 years old & 48.9389 & 131 & 7.76952 \\
\hline 14 years old & 47.3784 & 74 & 9.35114 \\
\hline 15 years old & 46.5385 & 26 & 8.82828 \\
\hline 16 years old & 44.1667 & 12 & 9.43719 \\
\hline
\end{tabular}

\begin{tabular}{|l|r|r|r|r|r|}
\hline & Sum of Squares & \multicolumn{1}{|c|}{ df } & Mean Square & F & Sig. \\
\hline Between Groups & 560.921 & 5 & 112.184 & 1.656 & .145 \\
Within Groups & 21202.189 & 313 & 67.739 & & \\
Total & 21763.110 & 318 & & & \\
\hline
\end{tabular}

\subsection{Moral identity and gender}

To answer question 2 that addressed the gender of adolescents, descriptive statistical analysis was conducted. Means, standard deviations and means percentage were computed. Results indicated that there is no significant difference in moral identity development due to gender. As shown in Table 2. 
Table 2. Participants' gender and moral identity

\begin{tabular}{|c|c|c|c|c|}
\hline gender & $\mathrm{N}$ & Mean & St. Deviation & Std. Error Mean \\
\hline Male & 154 & 47.5714 & 9.16505 & .73854 \\
Female & 162 & 47.7346 & 7.44820 & .58519 \\
\hline
\end{tabular}

\begin{tabular}{|l|c|c|c|c|c|c|c|}
\hline & \multicolumn{3}{|c|}{$\begin{array}{c}\text { Levene's Test for } \\
\text { Equality of Variances }\end{array}$} & \multicolumn{5}{|c|}{} \\
\cline { 2 - 7 } & $\mathrm{F}$ & Sig & $\mathrm{t}$ & $\mathrm{df}$ & $\begin{array}{c}\text { Sig. (2- } \\
\text { tailed) }\end{array}$ & $\begin{array}{c}\text { Mean } \\
\text { Difference }\end{array}$ & $\begin{array}{c}\text { Std. Error } \\
\text { Difference }\end{array}$ \\
\cline { 2 - 7 } & & & & & .862 & -.16314 & .93740 \\
$\begin{array}{l}\text { Equal variances } \\
\text { assumed } \\
\begin{array}{l}\text { Equal variances } \\
\text { not assumed }\end{array}\end{array}$ & 5.962 & .015 & -.174 & 314 & .863 & -.16314 & .94228 \\
\hline
\end{tabular}

\subsection{Moral identity and activity involvement}

To answer question 3 that addressed the significance of school activity involvement on moral identity, means and standards deviations of moral identity were computed. Then, one-way ANOVA was found. Results indicated that there is no significant difference in moral identity development due to school activity involvement as shown in Table 4.

Table 3. the distribution of students on school activities

\begin{tabular}{|l|c|c|c|}
\hline & $\mathrm{N}$ & Mean & Std. Deviation \\
\hline No activity involvement & 22 & 47.1818 & 9.01658 \\
Literary & 75 & 49.0667 & 7.98873 \\
Religious & 32 & 48.5625 & 6.45549 \\
Scientific & 55 & 45.1818 & 9.70317 \\
Cultural & 21 & 47.6190 & 6.65189 \\
Artistic & 37 & 48.2162 & 8.10739 \\
Sports & 77 & 47.4805 & 8.34552 \\
Total & 321 & 47.6573 & 8.27467 \\
\hline
\end{tabular}

Table 4. the involvement in school activities and moral identity

\begin{tabular}{|l|c|c|c|c|c|}
\hline & Sum of Squares & df & Mean Square & F & Sig. \\
\hline Between Groups & 547.366 & 7 & 78.195 & 1.146 & .334 \\
Within Groups & 21362.940 & 313 & 68.252 & & \\
Total & 21910.305 & 320 & & & \\
\hline
\end{tabular}

\section{Discussion}

This study focused on moral identity development among adolescents. It tested for the significance of adolescents' age and gender on their moral identity development. It also examined the influence of school activity participation on adolescents' moral identity development. The results of the study revealed that moral identity is not related to age, which is similar to a number of research studies (Hardy et al., 2013; Krettenauer, 2011; Pratt et al., 2003).

The results showed that girls had higher levels of moral identity than boys. However, the differences between boys and girls were not significant. This result is supported by previous studies that have not found any gender difference in moral identity (e.g., Aquino \& Reed, 2002). The result of this study comes inconsistent with some research studies, which found that there was a difference in moral identity between males and females (e.g., Hardy, 2006, Hardy et al., 2013). Other research studies found that females had higher levels of moral identity than males (e.g., Hardy, 2006).

The results showed that the involvement in school activities does not directly influence moral identity development. This result is inconsistent with the literature, which showed that school in general has a profound influence on one's identity (Moshman, 2004, 2005; Oyserman et al., 2012; Splitter, 2010), and moral identity (Bock \& Samuelson, 2015). This result indicates that Jordanian adolescents develop moral identity during this stage of their development, but their moral identity development is not associated with the involvement in particular school activities. This may be due to the fact that the Jordanian culture emphasized teaching morals and ethical guidance starting from childhood and it is embedded in all educational and parental activities. Considering the results of this study along with previous research, moral identity is a developmental facet of adolescence and the involvement in school activities fosters it. 


\section{References}

Berkowitz, M. W. (2012a). Moral and character education. In K. R. Harris, S. Graham, \& T. Urdan (Eds.), Educational Psychology Handbook (pp. 247- 264). Washington, DC, US: American Psychological Association.

Berkowitz, M.W. (2012b). You can't teach through a rat: And other epiphanies for educators. Boone, NC: Character Development Group.

Betawi, A. (2018). Calling for character education: Promoting moral integrity in early childhood education in Jordan. Early Child Development and Care, 1-12.

Bock, T., \& Samuelson, P. L. (2015). Educating for Moral Identity: An analysis of three moral identity constructs with implications for moral education. Journal of Research in Character Education, 10(2), 155.

Damon, W. (1984). Self-understanding and moral development from childhood to adolescence. In W. M. Kurtines, \& J. L. Gewitz (Eds.). Morality, moral behavior, and moral development (pp. 109- 127). New York, NY: Wiley.

Erikson, E. H. (1963). Childhood and society (2 $2^{\text {nd }}$ ed.). New York: Norton.

Erikson, E. H. (1968). Identity: Youth and crisis. New York, NY: Norton.

Frimer, J. A., \& Walker, L. J. (2009). Reconciling the self and morality: An empirical model of moral centrality development. Developmental Psychology, 45(6), 1669- 1681.

Hardy, S. A. (2006). Identity, reasoning, and emotion: An empirical comparison of three sources of moral motivation. Motivation and Emotion, 30(3), 205-213. doi:10.1007/s11031-006-9034-9

Hardy, S. A., Walker, L. J., Olsen, J. A., Woodbury, R. D., \& Hickman, J. R. (2013). Moral Identity as Moral Ideal Self: Links to Adolescent Outcomes. Developmental Psycology, 50(1), 45- 57.

Moshman, D. (2004). False moral identity: self-serving denial in the maintenance of moral self-conceptions. In D. K. Lapsley, \& D. Narvaez. (Eds.). Moral development, self, and Identity (pp. 83- 110). Mahwah, NJ: Erlbaum.

Moshman, D. (2005). Adolescent psychological development: Rationality, morality, and identity. Mahwah, NJ: Erlbaum.

Oyserman, D., Elmore, K., \& Smith, G. (2012). Self, self-concept, and identity. In M. R. Leary \& J. P.

Tangney (Eds.). Handbook of self and identity (pp. 69- 104). New York, NY: Guilford Press.

Pratt M. W., Hunsberger B., Pancer M., \& Alisat S. (2003). A longitudinal analysis of personal values socialization: Correlates of a moral self-ideal in late adolescence. Social Development.12(4), 564- 585.

Splitter, L. (2010). Identity, citizenship and moral education. Educational Philosophy and Theory, 43(5), $485-505$. 